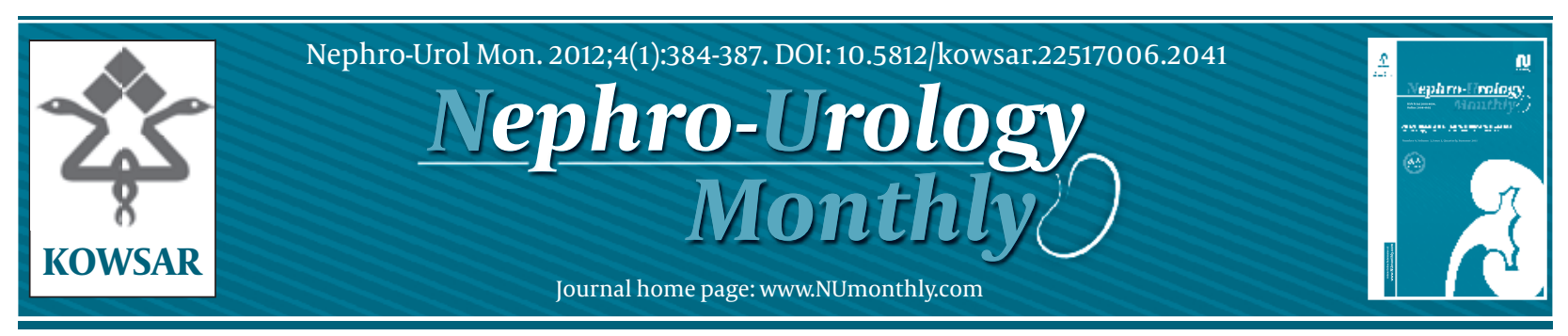

\title{
Acute Renal Failure as a Complication of Preoperative Ureter Catheter- ization for Colorectal Surgery
}

\author{
Kuldeep Singh ${ }^{1}$, Salim C. Saba ${ }^{1}$, Maxim Pekarev ${ }^{2}$, Martin Zomaya ${ }^{3}$, Sanjiv Patankar ${ }^{1}$ \\ ${ }^{1}$ Department of Colon and Rectal Surgery, St. Peter's University Hospital, New Brunswick, New Jersey, United States \\ 2 Department of Surgery, Drexel University College of Medicine and Hahnemann University Hospital, Philadelphia, Pennsylvania, United States \\ ${ }^{3}$ American University of the Caribbean, School of Medicine, Netherlands Antilles
}

\begin{tabular}{|c|c|}
\hline A R T I C L E I N F O & A B S T R A C T \\
\hline Article type: & We describe two cases of anuria secondary to prophylactic ureteral stenting in two pa- \\
\hline Case Report & tients who underwent laparoscopic colon resection. The intra-operative course was un- \\
\hline Article history: & $\begin{array}{l}\text { complicated and the stents were removed in the immediate post-operative period. The } \\
\text { anuria was accompanied by acute renal failure as evidenced by a rising serum creatinine. }\end{array}$ \\
\hline Received: 14 Mar 2011 & Retrograde ureterograms were used to demonstrate ureteral patency. Cystoscopy and \\
\hline Revised: 3 Apr 2011 & restenting within 48 hours resulted in prompt diuresis in both patients, with full recov- \\
\hline Accepted: 16 Apr 2011 & ery of renal function within one week. We believe that reflex anuria was the causative en- \\
\hline
\end{tabular}

Keywords:

Acute Kidny Failure

Colorectal Surgery

Catheterization

Copyright $\odot 2012$, Kowsar M.P.Co. All rights reserved.

Implication for health policy/practice/research/medical education:

Prophylactic ureteral stenting is a common and useful procedure performed during colorectal surgeries. Physicians should be made aware of the rare but serious complications of reflex anuria and acute renal failure caused by ureteral stenting.

- Please cite this paper as:

Singh K, Saba SC, Pekarev M, Zomaya M, Patankar S. Acute Renal Failure as a Complication of Preoperative Ureter Catheterization for Colorectal Surgery. Nephro-Urol Mon. 2012;4(1):384-7. DOI: 10.5812/kowsar.22517006.2041

\section{Introduction}

Inadvertent ureteral injury during complicated surgeries of the rectum and left colon ranges from 1-10\% (1-3). While some argue that ureteral stenting prior to colorectal surgery is a necessary step in reducing the number of iatrogenic injuries to the ureter, others contend that the value of stenting lies simply in helping the surgeon identify injury more easily $(1,4)$. With the advent of laparoscopy, identification of the ureters is rendered more challenging. In an effort to facilitate ureteral detection, especially during laparoscopic cases, lighted or illuminated ureteral stents have evolved with the aim of providing the surgeon with an improved visual dimension.

\footnotetext{
* Corresponding author: Martin Zomaya, American University of the Caribbean School of Medicine, Saint Martin, Netherlands Antilles. Tel: +15013195319,E-mail: martin.zomaya@gmail.com
}

DOI:10.5812/kowsar.22517006.2041

Copyright $\odot 2012$, Kowsar M.P.Co. All rights reserved.
In spite of these improvements however, injury to the ureters during difficult dissections, although rare, is still reported.

Although many colon and rectal surgeons advocate the prophylactic use of ureteral stents to safeguard against ureteral injury, the practice has been criticized as adding to cost and operative time, while being associated with significant morbidity $(5,6)$. Common complications that have been described include direct injury to the ureter and urinary tract infection (6). Less common but more serious complications have also been encountered. Among these is "reflex anuria", which results in the complete cessation of urine production in the post-operative period leading to acute renal failure. This rare condition is associated with ureteral catheterization and is explained by a reflex mechanism leading to arteriolar vasoconstriction and ureteral spasm (7). This article will document two cases of post-operative renal failure associated with 


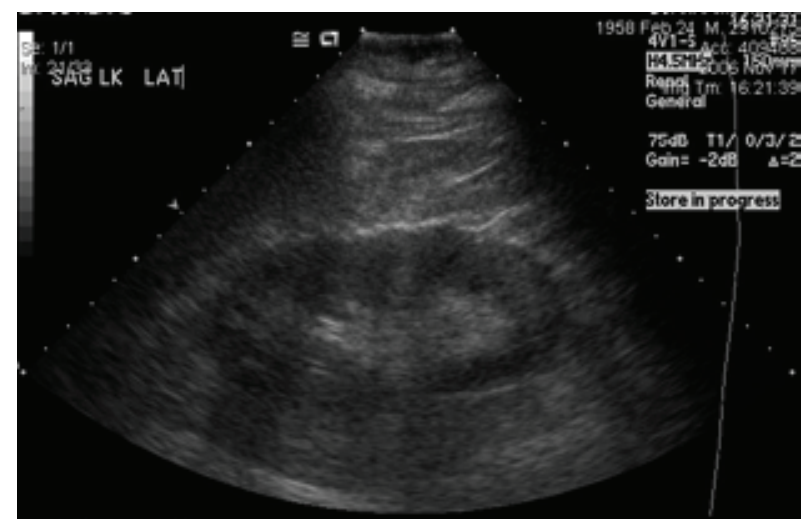

Figure 1. Left Kidney Ultrasound of Patient 1 Demonstrating a Normal Kidney With no Evidence of Hydronephrosis (The right kidney ultrasound showed no abnormalities).

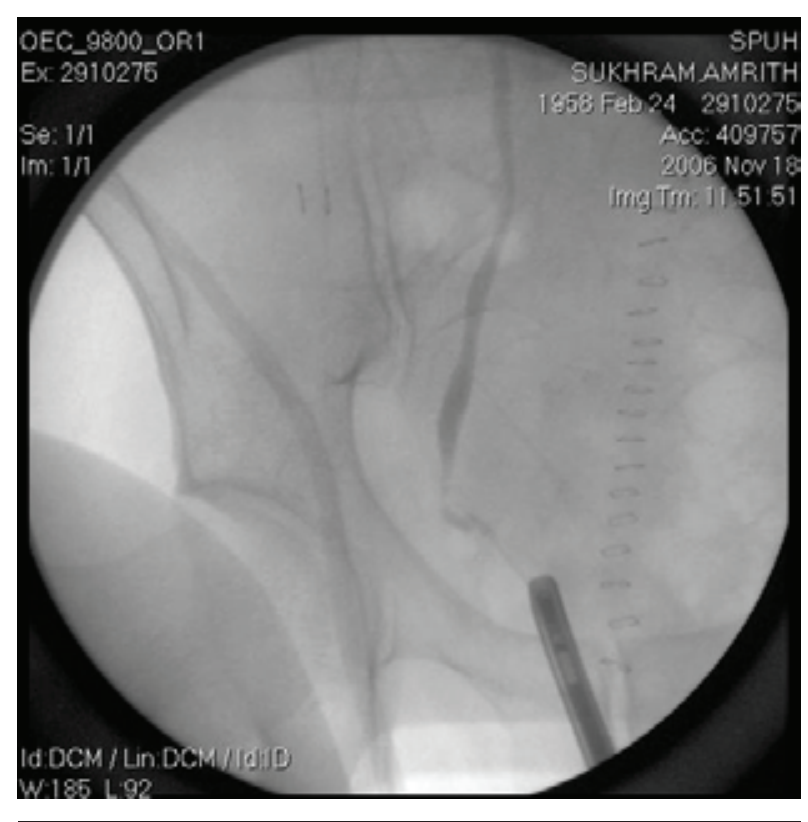

Figure 2. Retrograde Ureterogram of Patient 1 Demonstrating a Patent Right Ureter.

pre-operative bilateral ureteral stenting for colorectal surgery. Neither patient demonstrated any evidence of ureteral obstruction. However, following repeat ureteral catheterization both patients promptly duiresed and eventually recovered normal renal function, suggesting reflex anuria as the causative entity.

\section{Case 1}

A 48-year-old Indian male with no other medical history, except for recurrent diverticular disease, presented to our hospital for an elective laparoscopic sigmoid resection. Part of the pre-operative clearance included a full chemistry panel that showed a creatinine of $1.1 \mathrm{mg} / \mathrm{dL}$ (0.5-1.4 mg/dL). Bilateral Infravision (Stryker Endoscopy, Santa Clara, CA, USA) lighted stents were placed by an urologist prior to the procedure without any difficulty.
Laparoscopic dissection proved difficult due to multiple adhesions and the procedure was converted to an open one. The ureters could be identified and palpated and the sigmoid colon was resected without incident. The procedure was completed in approximately two hours with no significant blood loss, $1600 \mathrm{~mL}$ of crystalloid was infused and the patient produced $300 \mathrm{~mL}$ of clear urine. At the conclusion of the case, both stents were removed leaving the foley catheter in place. Immediately in the postoperative period and for the next 24 hours, the patient was oliguric producing only $10-20 \mathrm{~mL}$ of urine per hour.

Basic maneuvers that included changing the foley catheter yielded no improvement in the urine output. On the first post-operative day, the creatinine was $1.9 \mathrm{mg}$ / $\mathrm{dL}$ (0.5-1.4 mg/dL). Despite aggressive fluid resuscitation, the patient remained oliguric and within 36 hours postoperatively he became anuric. His creatinine continued to rise steadily, and reached $4.2 \mathrm{mg} / \mathrm{dL}$ at 42 hours postoperatively. An ultrasound was done that showed normal sized kidneys without evidence of hydronephrosis or hydroureter (Figure 1). Urine electrolyte values were sent for calculation of a fractional excretion of sodium and found to be consistent with a post-renal pathology. Additionally, cystoscopy was performed that showed normal appearing bladder mucosa and no evidence of edema at the ureteral orifices. A retrograde ureterogram was also performed and revealed no evidence of stricture or mechanical obstruction (Figure 2).

Upon repeat stenting of both ureters on the second post-operative day, there was immediate return of 900 $\mathrm{ml}$ of clear urine. Over the next 48 hours, the patient's creatinine was $1.2 \mathrm{mg} / \mathrm{dL}$. One stent was removed two days after placement, and the other was removed 3 days after. The foley catheter was also removed along with the second stent, and the patient continued to void normally with good urine output. The creatinine remained normal and the patient was discharged one week after surgery. At one-month follow up the patient's creatinine was $1.1 \mathrm{mg} / \mathrm{dL}$ and creatinine clearance was $106 \mathrm{ml} / \mathrm{min}$ ute (80-120 $\mathrm{mL} / \mathrm{min})$.

\section{Case 2}

A 62-year-old male with a low rectal cancer following neo-adjuvant chemotherapy, presented for a laparoscopic low anterior resection and diverting loop ileostomy. Aside from hypertension, the patient was otherwise healthy with a pre-operative creatinine of $0.8 \mathrm{mg} / \mathrm{dL}$. Preoperative cystoscopy and bilateral ureteral stenting were performed without difficulty. During the procedure, the ureters could be identified and palpated. The remainder of the procedure was completed without any adverse event. At 36-hours post-operatively, the patient remained oliguric despite aggressive fluid resuscitation. His creatinine at that time was $2.6 \mathrm{mg} / \mathrm{dL}$. An ultrasound of the kidneys showed mild hydronephrosis of the left collecting system. The patient was taken back to the operating room on the second post-operative day for cystoscopy. No 
obvious signs of injury or edema at the ureteral orifices could be appreciated. A ureterogram was done showing no signs of mechanical obstruction. Bilateral ureteral stents were inserted and the patient diuresed almost immediately. Within three days, the patient was still producing an adequate amount of urine, and there was a notable decrease of his creatinine. The stents were removed in a graded fashion and at the time of discharge on the eight post-operative days his creatinine was $1.2 \mathrm{mg} / \mathrm{dL}$.

\section{Discussion}

As laparoscopic colorectal procedures have gained popularity, the role of illuminated ureteral stents has become disputed in their importance to minimize iatrogenic ureteral injury. Although these stents are placed to prevent ureteral injury, they are not without complications. Most complications are due to traumatic stent insertions that result in ureteral tearing. Secondary complications include infections of the urinary tract several days following stent placement. Rarely, removal of the ureteral stents in the immediate post-operative period results in anuria and acute renal failure. This rare condition, known as reflex anuria, has only been described in the literature in the form of case presentations. Hull et al.(8) defined reflex anuria in 1979 as: 'Cessation of urine output from both kidneys in response to irritation or trauma to one kidney or its ureter or severely painful stimuli to other organs.' Sirota and Narins (9) were among the first to use the term 'reflex anuria' to describe oliguria or anuria in association with ureteral catheterization. Shearlock and Howards (10) reported on the first well-documented case of reflex anuria, using angiography to suggest that it was the direct result of a reflex mechanism caused by renal arteriolar vasoconstriction.

Varying mechanisms have been proposed to explain reflex anuria. The ureterorenal and the renorenal reflexes are examples of the neurovascular mechanism. The latter has been reported in the form of renal failure resulting from unilateral chemoembolization of a renal tumor (11). The ureterorenal reflex suggests that injury to one ureter can cause bilateral or contralateral renal arteriolar vasoconstriction. Fibers from the ureter that communicate with renal efferent vasoconstrictive fibers stimulate renal arterial vasoconstriction in response to pain or injury. Di Salvo and Fell (12) demonstrated cessation of renal blood flow using pulsatile renal nerve stimulation studies. Francisco et al. (13) however, conducted the analytical investigation utilizing the canine model to show a $20 \%$ decrease in contralateral renal blood flow with unilateral ureteral obstruction.

While there are many proponents of the neurovascular hypothesis, others have cited mechanical obstruction as the primary cause behind the anuria. Sheikh et al. implicated ureteral obstruction as an important factor in anuria following stent removal. ${ }^{1,6}$ They demonstrated edema of the ureterovesicular orifices on cystoscopy and stated that the anuria was due to an obstructive phenom- enon. Leff et al. (1) also cited edema at the uretervesical junction as the cause of post-stent anuria.

Reflex anuria via two different mechanisms can explain our observations. Both patients had normal pre-operative renal function that deteriorated following stent removal post-operatively. The removal of the stents may have caused renal failure secondary to a neurovascular reflex mechanism from irritation to one or both ureters. We did not obtain arteriographic or scintigraphic evidence however, to support or to disprove this. Pain is not a key factor in either case as pain was well-controlled in both patients. Ureteral spasm cannot be excluded either, despite the failure of ultrasound to demonstrate a significant degree of hydronephrosis. We believe that an ultrasound performed within 48 hours would not have allowed enough time for the development of hydronephrosis apparent on imaging. Additionally, a normal ureterogram does not exclude ureteral spasm as back pressure from the dye is sufficient to overcome the pressure caused by the spasm. Obstruction secondary to edema is not supported as cystoscopy failed to demonstrate edema at the ureterovesicular orifices.

Many mechanisms surrounding the pathophysiology of anuria associated with ureteral stenting have been proposed. Some believe the anuria is purely due to a mechanical obstruction caused by edema at the uretrovesicular junction. Those that support the concept of reflex anuria have proposed two mechanisms; neurovascular reflex resulting in profound arteriolar vasoconstriction, and bilateral ureteral spasm secondary to unilateral ureteral or renal parenchymal damage. We propose that both mechanisms are plausible in the anuria that resulted in both of our patients.

Prevention of ureteral injury during colorectal surgery begins with a thorough knowledge of pelvic anatomy, proper exposure, and good surgical technique. Although urinary tract injuries are uncommon, the ureters or bladder may be injured if significant inflammation is present leading to poor differentiation of tissue planes. Dissection should be precise. However, this can be difficult, especially in laparoscopic cases. To overcome these difficulties, some surgeons use illuminated stents. Normally, these stents are removed in the immediate postoperative period without incident. Rarely however, anuria associated with these stents can develop, and may be mediated by a neurovascular and obstructive mechanism. Although reflex anuria is rare, it should always be considered in a well hydrated patient that becomes anuric after ureteral catheterization or manipulation. We recommend immediate cystoscopy and restenting of the ureters if no other obvious causes are identified. The stents should be removed in a graded fashion at least 24 hours apart to prevent recurrence.

\section{Acknowledgments}

None declared. 


\section{Financial Disclosure}

None declared.

\section{Funding/Support}

None declared.

\section{References}

1. Leff EI, Groff W, Rubin RJ, Eisenstat TE, Salvati EP. Use of ureteral catheters in colonic and rectal surgery. Dis Colon Rectum. 1982;25(5):457-60.

2. Tank ES, Ernst CB, Woolson ST, Lapides J. Urinary tract complications of anorectal surgery. Am J Surg. 1972;123(1):118-22.

3. Andersson A, Bergdahl L. Urologic complications following abdominoperineal resection of the rectum. Arch Surg. 1976;111(9):969-71.

4. Higgins CC. Ureteral injuries during surgery. A review of 87 cases. JAMA. 1967;199(2):82-8.
5. Chahin F, Dwivedi AJ, Paramesh A, Chau W, Agrawal S, Chahin $\mathrm{C}$, et al. The implications of lighted ureteral stenting in laparoscopic colectomy. JSLS. 2002;6(1):49-52.

6. Sheikh FA, Khubchandani IT. Prophylactic ureteric catheters in colon surgery-how safe are they? Report of three cases. Dis Colon Rectum.1990;33(6):508-10.

7. Songco A, Rattner W. Reflex anuria. Urology. 1987;29(4):432-3.

8. Hull JD, Kumar S, Pletka PG. Reflex anuria from unilateral ureteral obstruction. J Urol.1980;123(2):265-6.

9. Sirota JH, Narins L. Acute urinary suppression after ureteral catheterization; the pathogenesis of reflex anuria. $N$ Engl J Med. 1957;257(23):1111-3.

10. Shearlock KT, Howards SS. Post-obstructive anuria: a documented entity. J Urol. 1976;115(2):212-3.

11. Kervancioglu S, Sirikci A, Erbagci A. Reflex anuria after renal tumor embolization. Cardiovasc Intervent Radiol. 2007;30(2):304-6.

12. DiSalvo J, Fell C. Changes in renal blood flow during renal nerve stimulation. Proc Soc Exp Biol Med.1971;136(1):150-3.

13. Francisco LL, Hoversten LG, DiBona GF. Renal nerves in the compensatory adaptation to ureteral occlusion. Am J Physiol. 1980;238(3):F229-34 